\title{
Construct of Psychological Preparedness and its Correlates
}

\author{
Lokesh Gupta $^{1 *}$, Anjali Malik², Rajbir Singh ${ }^{2}$
}

\section{ABSTRACT}

Psychological preparedness is a term describing personal processes and capacity, including concern, anticipation, arousal, feeling, intentions, decision-making and management of one's thought feeling and actions (Reser\& Morrissey, 2009). In current study to construe the phenomenon of psychological preparedness among adult for specific short term and long term life events, episodes and stages. Research questions: (a) What does psychological preparedness constitute, (b) What are its personality correlates, (c) Can psychological preparedness be educated/trained or imbibed. (d) What is its predictive validity and (e) what are the criterion (intra and inter situation). To answer these research questions a sample of 200 adult shall be taken and personality correlates like resilience, mobility and liability of the nervous system, selfefficacy, time perspective and Bhagavad Gita's concept Nishkam karma will be measured. A bilingual (Hindi \& English) battery shall be prepared which can address questions and its psychometric properties shall be evaluated.

Keywords: Psychological Preparedness, Resilience and Self-efficacy.

Psychological preparedness is a term describing personal processes and capacity, including concern, anticipation, arousal, feeling, intentions, decision-making and management of one's thought feeling and actions (Reser\& Morrissey, 2009). There has been less focus on individual psychological preparedness by psychologists so far. Psychological preparedness can assist people to feel more confident and more in control and to use rational thinking when he responds to situation. Most of the research in the area of psychological preparedness has been conducted in the area of disaster management.

In current research psychological preparedness has been taking as a general phenomenon of a person and an attempt has been made to construct items relating to psychological preparedness. To fulfill this purpose psychological preparedness has been divided into seven facets (1) Concern, (2) Anticipation, (3) Arousal, (4) Feeling, (5) Intentions, (6) Decision-making and (7)

\footnotetext{
${ }^{1}$ Research Associate (RA), DIPR, DRDO, Delhi

${ }^{2}$ Professor, Department of Psychology, Maharshi Dayanand University, Rohtak

*Responding Author (C) 2016 I L Gupta, A Malik, R Singh; licensee IJIP. This is an Open Access Research distributed under the terms of the Creative Commons Attribution License (http://creativecommons.org/licenses/by/2.0), which permits unrestricted use, distribution, and reproduction in any Medium, provided the original work is properly cited.
} 
Management of thought feeling and action. These facets include person's cognitive, affective and temperamental aspects.

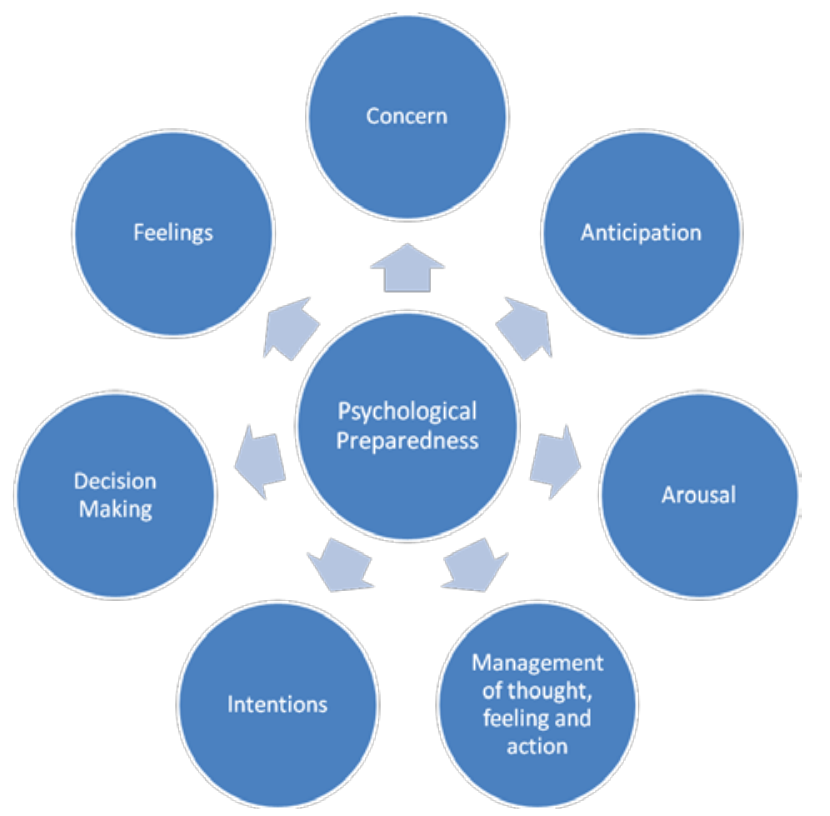

Psychological Preparedness and its seven facets

\section{Concern}

A matter that engages a person's attention, interest or care, or that affects a person's welfare or happiness.

\section{Anticipation}

Anticipation is a central motivating force in everyday life - 'the normal process of imaginative anticipation of, or speculation about the future. To enjoy one's life, one needs a belief in time as a promising medium to do things in, one needs to be able suffer the pains and pleasure of anticipation and deferral. Be aware or prepare for future events.

Arousal

Arousal is a physiological and psychological state of being awake or reactive to stimuli and a condition of sensory alertness, mobility and readiness to respond. Arousal is important in regulating consciousness, attention and information processing

\section{Management Of Thought, Feeling And Action}

Feel more confident and more in control and to use rational and clear thinking when responding to a situation.

\section{Intention}

In performing an action is his or her specific purpose in doing so, the end or goal that is aimed at, or intend to accomplish.

\section{Decision Making}

The thought process for assessing and choosing among several alternatives. A process that involves evaluating given information, making a judgment and based on these making a choice among several possible alternatives. 


\section{Feelings}

In Psychology, feeling is used for conscious subjective experience of emotion. Feelings are also known as a state of consciousness, such as that resulting from emotions, sentiments or desires.

\section{Psychological preparedness for what?}

The next question is Psychological preparedness for what? To answer this question a person's general life situation can be divided into three parts (A) Life Events, (B) Life Episodes and (B) Life Stages.

(A)Life Events: - Psychological preparedness for short term and specific period like: Exam, interview, short term journey, meeting etc.

(B) Life Episodes: - Psychological preparedness for long term (for 10-15 days) like: Training program, a long journey, examination period, camps, workshop, planning for upcoming events etc.

(C) Life Stages: - Psychological preparedness for long period like: Permanent job, Marriage, Adulthood, Career planning, financial investment etc.

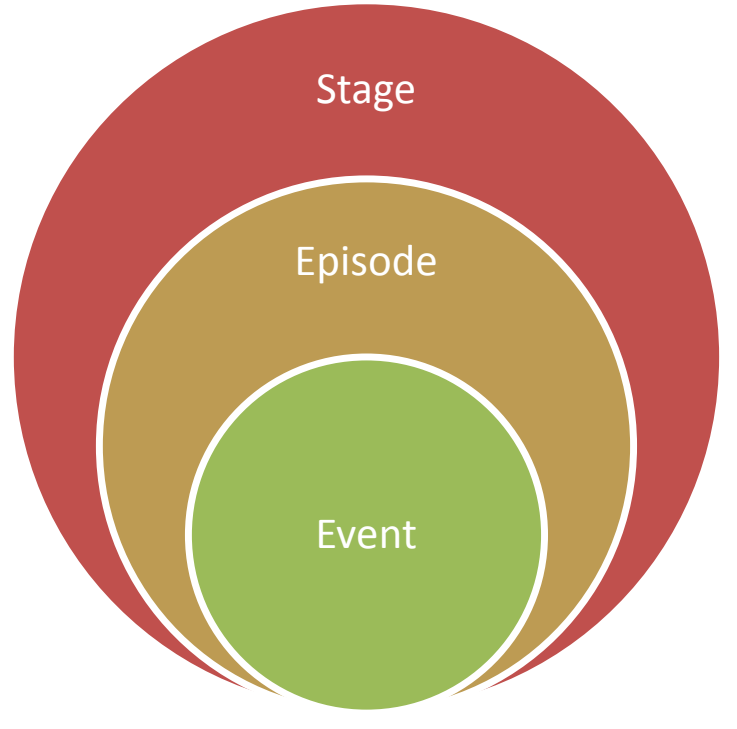

\section{Person's general life situation}

\section{OBJECTIVE}

1. Identifying facets of Psychological preparedness.

2. Define levels of Psychological preparedness.

3. Construction of a tool for measuring Psychological preparedness for adult (Hindi). 


\section{METHODS}

The present research is aimed at developing a scale for measuring psychological preparedness. In the concept of psychological preparedness is related to emotional readiness of an individual to react to any situation. According to American Psychological Society (APS, 2007), psychological preparedness involves "processes and capacities such as knowledge, anticipation, recognition, thinking, feeling, decision making and the management of one's own thought, feeling and actions.”

Since psychological preparedness seems to be a phenomenon with such broad scope, it is a matter of serious concern that's no scale has been developed to focus of individual's psychological preparedness to deal with day-to-day matter. The present research is focus on filling this lacuna. To fulfill this purpose psychological preparedness has been divided into seven facets on the bases of above definition by Reser\& Morrissey, 2009. (1) Concern, (2) Anticipation, (3) Arousal, (4) Feeling, (5) Intentions, (6) Decision-making and (7) Management of thought feeling and action.

The next step was to operationally define all seven facets of this definition. An attempt was make to measure these facets along three dimensions of Life events, Life episodes and Life stages.

\section{Item construction}

Each facet was dividing along the above mention three dimensions of life situation for each dimension four items were constructed keeping in mind typical situation faced by all individuals in day-to-day life. For each life dimension two positive and two negative items were constructed. For each item responses had to be marked five point scale "Strongly Disagree", "Disagree", ”Neutral”, “Agree” and "Strongly agree”

\section{RESULTS AND DISCUSSION}

To achieve the purpose of construction a tool for measuring psychological preparedness 86 items were constructed. After construction of items test were given to four experts (Professors of psychology) for rating each item on five-point scale. Average rating of each items showing on table-1. In this table average rating 1.25 is given for 8 items, 1.50 is given for 12 items and 2.00 is given for 18 items. 
Table-1, Average rating of each item

\begin{tabular}{|c|c|c|c|c|c|c|c|c|}
\hline & 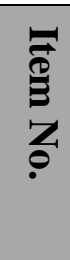 & 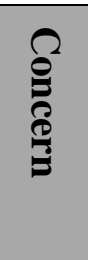 & 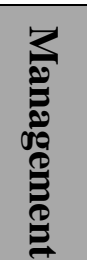 & 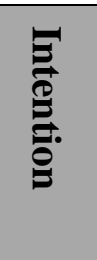 & 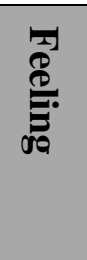 & 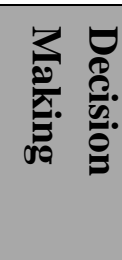 & 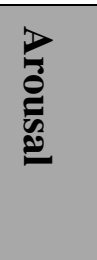 & 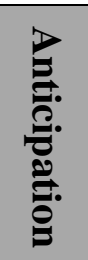 \\
\hline $\begin{array}{l}\text { 至 } \\
\stackrel{\Xi}{ٍ}\end{array}$ & $\begin{array}{l}1 \\
2 \\
3 \\
4 \\
5\end{array}$ & $\begin{array}{l}1.75 \\
2.00 \\
2.50 \\
2.00\end{array}$ & $\begin{array}{l}2.25 \\
2.25 \\
1.25 \\
2.25\end{array}$ & $\begin{array}{l}1.50 \\
2.75 \\
3.00 \\
3.50 \\
2.00\end{array}$ & $\begin{array}{l}1.50 \\
1.50 \\
1.75 \\
2.50\end{array}$ & $\begin{array}{l}1.50 \\
2.00 \\
2.25 \\
2.75\end{array}$ & $\begin{array}{l}1.50 \\
2.00 \\
1.25 \\
1.25\end{array}$ & $\begin{array}{l}1.50 \\
2.50 \\
1.25 \\
3.00\end{array}$ \\
\hline 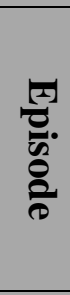 & $\begin{array}{l}1 \\
2 \\
3 \\
4 \\
5\end{array}$ & $\begin{array}{l}2.00 \\
2.50 \\
2.25 \\
1.25\end{array}$ & $\begin{array}{l}2.00 \\
1.75 \\
3.00 \\
2.75\end{array}$ & $\begin{array}{l}2.00 \\
2.00 \\
1.25 \\
3.50\end{array}$ & $\begin{array}{l}2.75 \\
1.75 \\
1.75 \\
2.50\end{array}$ & $\begin{array}{l}2.00 \\
2.25 \\
1.75 \\
2.50\end{array}$ & $\begin{array}{l}1.50 \\
2.25 \\
2.00 \\
2.50\end{array}$ & $\begin{array}{l}2.00 \\
1.50 \\
2.25 \\
2.00\end{array}$ \\
\hline 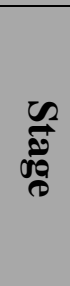 & $\begin{array}{l}1 \\
2 \\
3 \\
4 \\
5\end{array}$ & $\begin{array}{l}2.50 \\
1.25 \\
2.75 \\
2.00\end{array}$ & $\begin{array}{l}1.25 \\
2.00 \\
2.50 \\
1.50\end{array}$ & $\begin{array}{l}1.50 \\
2.00 \\
3.00 \\
2.75\end{array}$ & $\begin{array}{l}2.25 \\
1.50 \\
2.25 \\
1.50\end{array}$ & $\begin{array}{l}2.75 \\
2.25 \\
2.75 \\
1.75 \\
2.00\end{array}$ & $\begin{array}{l}2.50 \\
1.75 \\
2.00 \\
2.50\end{array}$ & $\begin{array}{l}2.75 \\
3.00 \\
3.25 \\
3.50\end{array}$ \\
\hline
\end{tabular}

Psychological preparedness and its personality correlates: -

Psychological preparedness and it personality correlates like Resilience, Mobility and liability of the nervous system, self-efficacy, Time perspective and Nishkam karma.

\section{Resilience: -}

Resilience has been divided as a universal capacity, which allows a person group or community to prevent, minimize or overcome damaging effects of adversity (Newman, 2004)

\section{Mobility and Lability of nervous system: -}

Strelau et al (1990) refers to mobility comprising of following five definitional components. A high mobile person: - (1) Reacts adequately to unexpected changes in environment, (2) Adapts quickly to new surroundings, (3) Passes easily from one activity to another, (4) Change mood lightly from positive to negative and vice versa, according to the meaning of the situation and (5) Refer situations which require different activities to be performed simultaneously. Uktomskii's (1937) defines Lability as the speed with which a psychological structure is able to pass from a state of rest to a state of excitation, and vice-versa, ready for the new response. Conceptually it seems that lability is a broader term, which may be inclusive of mobility. 


\section{Self-Efficacy: -}

It is an expectancy belief (expectation) how competently one will be able to enact a behaviour in a particular situation. Our elf-efficacy beliefs are the result of four type of information: - (1) Our experience trying to perform the target behaviour or similar behaviour (our past successes and failure), (2) Watching others perform that or similar behaviours (Vicarious experience), (3) Verbal persuasion (encouraging or discouraging performance) and (4) How we feel about behaviour (emotional reactions).

\section{Time perspective: -}

All the person, everywhere is oriented periodically toward the past, the present and the future. Lewin, 1951 the totality of the individuals vies of his psychological future and psychological past existing at a given time. Time orientation is a healthy sign different walk of life e.g. in business world, scientific world, socialization, planning a career, vocation as so on. The orientation may be seen as a characteristic of motivational process (Thomace, 1965)

\section{Nishkam Karma: -}

Nishkam karma or self-less or desire less action is an action performed without any expectation of fruits or results, and the central tenet of karma yoga path to liberation and stepping beyond personal goals and agendas while pursuing any action over greater good. Nihkam karma ha been variously explained as 'Duty for duty's sake' and as 'detached involvement' which is neither negative attitude nor indifference.

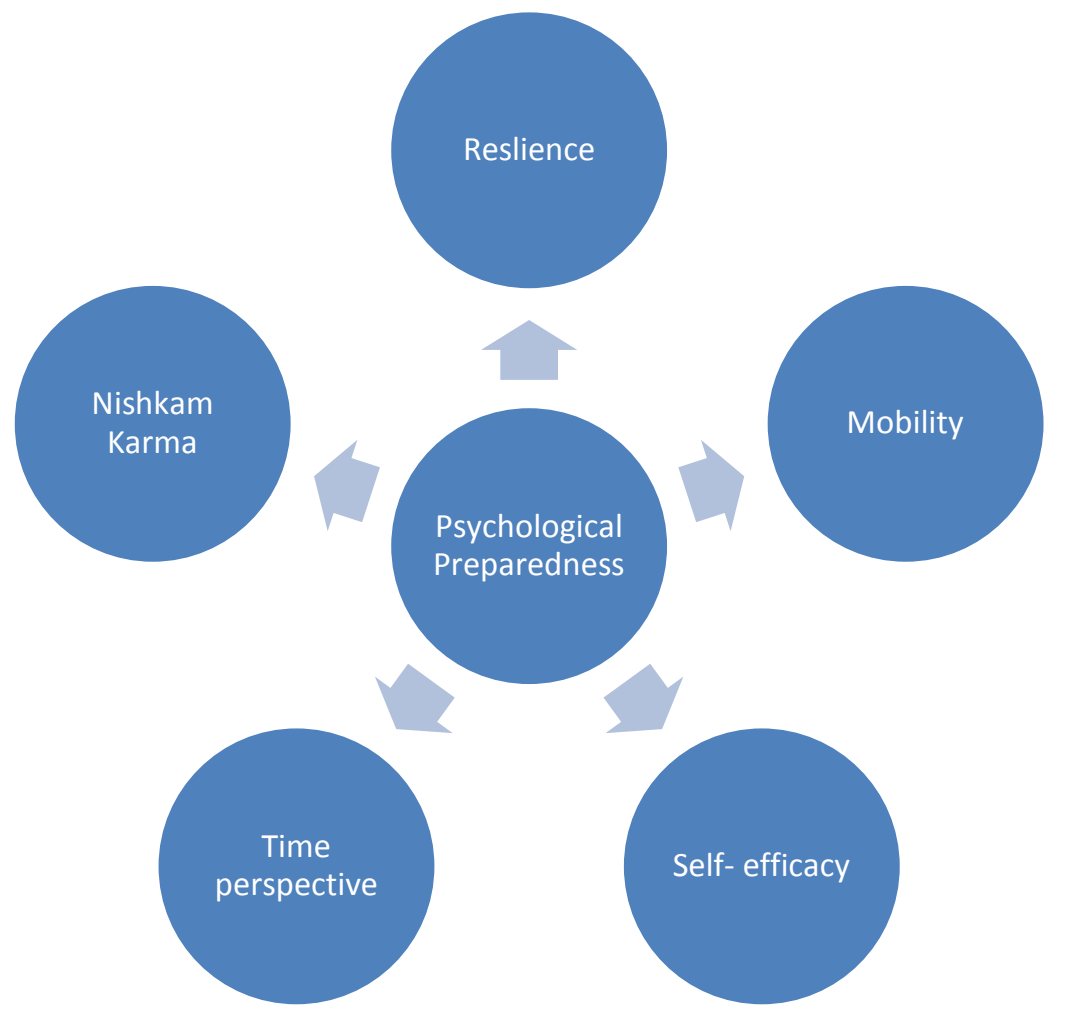

\section{Psychological Preparedness and its Personality Correlates}




\section{REFERENCE}

Australian Psychological Society. (2007). Preparing for and coping with the threat and experience of natural disasters. Melbourne: APS www.psychology.org.au.

Reser, J. P., \& Morrissey, S. (2009). The crucial role of the psychological preparedness for disasters. Retrieved 11 August 2009, from<http://www.psychological.org.au/ in psych/psychological_preparedness/>

Newman, T. (2004) What Works in Building Resilience. Barkingside: Barnardo’s

Strelau, J., Angleitner, A., Bantelmann, J., \&Ruch, W. (1990). The Strelau Temperament Inventory-Revised (STI-R). Theoretical considerations and scale development. European Journal of Personality, 4, 209-235.

Ukhtomskii, A. A. (1937). Fiziologicheskoypokoy i labil 'nost Kakbiologicheskiefaktory. Uchenyne Zapiski LGU, 17 (in Russian).

Lewin, K. (1951). The nature of field theory. In: M.H. Marx, Psychological Theories. New York: Macmillan.

Thomae, H. (1965). Zurallgemcinoncharakteristik des motivations geschchens. In: H. Tohmae (Ed.), Allgemein Psychologie II. Motivation Handbook de Psychologia, 2. Gottingen: Hogrefe. 